\title{
TEORÍA CRÍTICA DE LA SOCIEDAD \\ -O LA FILOSOFÍA COMO INVESTIGACIÓN
}

\author{
Ciro Alegría Varona
}

Pontificia Universidad Católica del Perú

La teoría crítica de la sociedad es una de las grandes vertientes de la filosofía contemporánea, al lado del análisis del lenguaje, el pragmatismo, el estructuralismo y la fenomenología, por mencionar sólo denominaciones muy diferenciadas. La intención que anima a la teoría crítica de la sociedad es producir una forma de crítica moral inmanente que no se apoye en principios a priori de la razón, sino en las nociones normativas que operan en el acontecer social, psíquico e histórico. En el rechazo del apriorismo, la teoría crítica de la sociedad (en adelante TCS) pertenece al mismo género de filosofía que las otras escuelas contemporáneas mencionadas, porque puede decirse que todas se proponen, por diversos medios, librar de supuestas estructuras inmutables y eternas el uso inmanente de la razón que Kant había descubierto. La gran idea kantiana, la idea fundadora de nuestro tiempo, es que la metafísica puede ser recuperada críticamente si se distinguen los juicios teóricos y experienciales de los juicios prácticos y teleológicos. Llamemos metafísica, en el sentido kantiano, al conjunto de concepciones sobre el nexo entre naturaleza y libertad proveedoras de motivaciones reflexivas. Lo que Kant consiguió con la distinción entre los juicios de conocimiento y los juicios sobre el bien y el mal es desbloquear la investigación de las condiciones de una vida humana libre. La metafísica dogmática, en sus diversas y contradictorias formas, había logrado encerrar la idea de libertad dentro de los límites de supuestos conocimientos objetivos sobre sus fundamentos, en juicios como que no hay vida buena sin sujeción al monarca, a la lglesia o al varón cabeza de familia. Ello se había consumado mediante el uso teórico 
de la razón especulativa, la que se suponía capaz de intuir intelectualmente realidades trascendentes. Al negarle a la razón especulativa todo significado que no sea el de la motivación moral, la filosofía crítica "transforma su uso trascendente en inmanente", es decir, muestra que la razón es, "mediante las ideas, causa actuante en el campo de la experiencia"'. Las mencionadas corrientes filosóficas del presente comparten este propósito kantiano, pero al mismo tiempo comparten el rechazo a la suposición kantiana de un sujeto trascendental completamente separado del flujo de la experiencia, un sujeto cuyos principios teóricos y prácticos pudieran conocerse a priori. La diferencia específica que caracteriza a la TCS en medio de la filosofía contemporánea es la pretensión de encontrar en los fenómenos sociales criterios normativos para denunciar formas de organización social injustas y dar paso a otras que sean más favorables a la emancipación y realización humanas.

La filosofía crítica, al convertirse en crítica social, se ha apartado del análisis de las condiciones formales que hacen posible a la razón, ha abandonado el elemento de la teoría trascendental y se ha transformado en órgano de la crítica inmanente de la sociedad. Con arraigo en una recepción muy particular de Hegel y de Marx (mediada por "la izquierda hegeliana" y "el joven Marx"), la TCS asume que tanto las exigencias morales entre individuos como las luchas sociales entre grupos son fenómenos en que acontece la determinación de la libertad humana. No sabríamos qué implica concretamente la idea de dignidad humana ${ }^{2}$ si no fuéramos capaces de encontrarla encarnada en la justa indignación de los individuos ante la explotación y la cosificación que sufren bajo determinadas condiciones sociales.

\footnotetext{
I "Denn das moralische Gesetz beweiset seine Realität dadurch [...], daß es einer blos negativ gedachten Causalität [...] positive Bestimmung [...] hinzufügt und so der Vernunft, die mit ihren Ideen, wenn sie speculativ verfahren wollte, immer überschwenglich wurde, zum erstenmale objective, obgleich nur praktische Realität zu geben vermag und ihren transscendenten Gebrauch in einen immanenten (im Felde der Erfahrung durch Ideen selbst wirkende Ursachen zu sein) verwandelt" (Kant, Immanuel, Crítica de la razón práctica, Analítica I. De la deducción de los principios de la razón práctica, Akademie Ausgabe $\mathrm{V}, 48$ ).

2 Kant mismo admitió que, bajo las premisas del apriorismo, la manera concreta en que la ley moral motiva a realizar una determinada conducta "es un problema insoluble para la razón humana": "Denn wie ein Gesetz für sich und unmittelbar Bestimmungsgrund des Willens sein könne (welches doch das Wesentliche aller Moralität ist), das ist ein für die menschliche Vernunft unauflösliches Problem und mit dem einerlei: wie ein freier Wille möglich sei" (ibid., Analítica III. De los móviles de la razón práctica pura, V, 72).
} 
La TCS, debido a su forma social de pensar la inmanencia del criterio normativo, está enfrentada a otras corrientes de la filosofía contemporánea. El análisis del lenguaje, por ejemplo, le reprocha a la TCS que cometa la falacia de cuestionar juicios morales mediante la denuncia de las condiciones socioeconómicas en que esos juicios morales tienen lugar. Desde un punto de vista lógico, no son las condiciones sociales que acompañan a una posición normativa lo que determina si esta es moral o inmoral, justa o injusta; un juicio moral sólo puede ser cuestionado por otro juicio moral ${ }^{3}$. La respuesta de la TCS a estos cargos es que los juicios morales, como son actos de habla, se definen en un contexto social, y no sabríamos a qué se refiere, por ejemplo, la idea de igual dignidad de todo ser humano, ni la idea de respeto, si no las recogiéramos de su uso en la praxis social, a menos que pretendiéramos que el lenguaje tiene una realidad subyacente, una gramática universal o algo así, que puede conocerse sin referencia a la praxis social. En este debate, el estructuralismo y el pragmatismo mantienen posiciones afines a la TCS.

En el punto de partida de la TCS está la crítica de Hegel a Kant. Hegel concentró sus ataques en el carácter a priori del principio moral, por considerar inaceptable que la autocomprensión moral termine en la mención de un misterio del corazón humano. Según Hegel, la noción de lo incondicionado es nula en la práctica porque, debido a su indeterminación, no puede derivarse de ella ninguna consecuencia específica para la acción, pues toda acción real ocurre inevitablemente bajo ciertas condiciones. Como alternativa a Kant, Hegel sostuvo que la negatividad de toda idea normativa, su universalidad, tiene un lugar $y$ un momento en medio del proceso concreto de la praxis y no puede pensarse exenta de condiciones materiales. La verdadera universalidad es negación determinada, negación de algo, no mera y pura anulación de toda referencia particular. La vida moral queda así historizada, temporalizada, inscrita en un encadenamiento causal. Para evitar que el valor moral quede falazmente mezclado con los hechos y subordinado a la fuerza de las cosas, es decir, para no recaer en el dogmatismo que Kant criticó, Hegel añade que el proceso histórico no anula la libertad porque él mismo está regido por ella. El problema subsistente es entonces concebir el proceso histórico universal como realización de la libertad sin incurrir en la justificación de lo

3 Cf. Tugendhat, Enst, Lecciones de ética, Barcelona: Gedisa, 1997, capítulo I. 
injustificable, es decir, sin perder el sentido crítico. El famoso quiasmo "lo que es racional es real y lo que es real es racional" del Prólogo a su Filosofía del derecho despertó sospechas -y lo sigue haciendo- de que su filosofía da por racional todo lo que ocurre, como una versión elaborada de la ley del más fuerte. En vez de eludir estas sospechas con declaraciones moralistas, que hubieran sido fáciles de hacer, Hegel, en su madurez, se dedica a captar cómo la libertad se abre paso a través de los conflictos materiales e intelectuales de su tiempo, pues para él la filosofía no es más que "su tiempo aprehendido en pensamientos"4. Uno de los asistentes a esas lecciones, el joven Marx, tomó en serio esta tarea de la filosofía y radicalizó el programa filosófico hegeliano mediante una investigación empírica de las contradicciones constitutivas del sistema económico capitalista.

La transformación de la dialéctica hegeliana por el joven Marx es una de las ideas impulsoras de la TCS. La confrontación Marx-Hegel se da en el terreno de la crítica del capitalismo. Hegel mostraba que el nuevo orden social basado en el "principio de individualidad" y el "sistema de las necesidades" sólo puede estabilizarse mediante nuevas instituciones, la familia nuclear, la sociedad civil y el Estado social y representativo. El joven Marx cuestiona la solución institucionalista con el argumento de que el capital absorbe e instrumentaliza todo valor individual y social. Junto a la creciente deshumanización y cosificación que penetra en la cultura y destruye su contenido normativo, crece también la irracionalidad del sistema económico que cae, por ello, en crisis cada vez más graves y recurrentes. Más tarde, en tiempos en que escribía El capital, Marx estaba ya lejos de limitarse a sistematizar su diagnóstico de la cosificación, elaboraba más bien una teoría de las crisis económicas y de la transformación revolucionaria del manejo del capital, con el propósito de superar las crisis y dar lugar a un desarrollo formidable de las fuerzas productivas que disolvería los problemas de justicia social en medio de la abundancia. La Revolución rusa dogmatizó este segundo aspecto de la obra de Marx, lo convirtió en el método infalible del progreso económico y cultural del socialismo y, mientras tanto, silenció la crítica de la cosificación. 
Fueron los marxistas europeos los que retomaron el diagnóstico de la sociedad moderna en busca de su potencial de crítica inmanente, en particular Georg Lukács y Ernst Bloch. De jóvenes, ellos recibieron a través de Max Weber, su maestro y amigo en Heidelberg, múltiples perspectivas de crítica de la racionalidad de la sociedad moderna. En Weber operaba la influencia de Nietzsche cuando detectó que el elemento ideológico de la acumulación capitalista es la ética protestante. El ascetismo de la ética protestante llama a consagrar toda ganancia al incremento de las oportunidades de trabajo y producción, de forma que cada vez más personas adopten esas normas ascéticas y se hagan dignas de la salvación eterna. Con ello, la ética protestante, según Max Weber, pone inconscientemente las bases de una sociedad totalmente dedicada al incremento de los medios productivos. Lukács escapó pronto a las dificultades que este tipo de crítica tiene en la práctica. Su Teoría de la novela auguraba el surgimiento de una disposición de los seres humanos a asumir la tarea de redención de la humanidad, en medio de la crisis definitiva de la cultura del temor a una divinidad trascendente. Junto con el Espíritu de la utopía de Ernst Bloch, un manifiesto místico-revolucionario, formaban la avanzada (extrauniversitaria, por supuesto) de una nueva forma de hacer crítica de la época. El interés de Lukács por Marx no estuvo nunca separado de la crítica de los dogmatismos y encierros mentales característicos de la sociedad moderna. En las obras de Lukács El joven Hegel y la sociedad capitalista e Historia y conciencia de clase se establecieron los vasos comunicantes entre la positivización (dogmatismo estatutario, objetivista) de la vida espiritual y la cosificación del valor de la vida humana como trabajo alienado.

La TCS está históricamente vinculada al Instituto de Investigación Social de Frankfurt fundado en 1924 por iniciativa de Félix Weil, mecenas de los estudios marxistas ${ }^{5}$. El grupo iniciador se formó en seminarios libres alrededor de las obras de Georg Lukács y Karl Korsch. En los primeros años, bajo la dirección de Carl Grünberg, los esfuerzos del Instituto se concentraron en estudios sobre el movimiento obrero, la formación de la biblioteca, la colección documentaly la edición de las obras de Marx. Una excepción a ese espectro de temas fue ya en esos comienzos Leo Löwenthal, que investigó la novela alemana en el siglo XIX. Pero la formidable dinámica de investigación y creación filosófica que se

5 Cf. Wiggershaus, Rolf, La Escuela de Fráncfort, Buenos Aires: FCE, 2010. 
asocia al Instituto se debe en gran parte a la dirección de Max Horkheimer, quien ocupó ese cargo en Frankfurt apenas por tres años, de 1930 a 1933. Al asumir la dirección del Instituto, la Universidad de Frankfurt le confirió una cátedra de filosofía social, que respondía a la necesidad de comprender el nexo entre el proceso económico, los procesos psíquicos de los individuos y los cambios culturales. Se trataba de poner las bases éticas y científicas para una sociedad menos injusta y arbitraria, menos requerida, por tanto, de idealismos radicales. Este camino corría apartado tanto del optimismo revolucionario como de la consideración melancólica de la enorme responsabilidad de la existencia humana individual que planteaba Heidegger. Formado en la escuela psicológica de la Gestalt, que combinaba elementos de filosofía trascendental con ideas positivistas de progreso mediante la ciencia, Horkheimer fue también un lector fiel de Schopenhauer, de quien recibió un agudo sentido de la fragilidad del saber y de los proyectos colectivos. Su personalidad intelectual resume bien la atmósfera del Instituto. Él no era el único protagonista, pues Leo Löwenthal fue el encargado de conversar con Erich Fromm, primero, y después con Herbert Marcuse, para integrarlos; Löwenthal también vinculó en investigaciones históricas a Norbert Elias y Franz Borkenau. La ampliación de la crítica social, a partir de un núcleo de diagnóstico económico, hacia la psicología y la cultura era una preparación de este grupo de intelectuales judíos para sobrevivir a la catástrofe de Europa que ya se veía venir. La captación de la tenaz maraña del poder les era necesaria para mantenerse activos como filósofos sociales en medio de la ruina de la precaria entidad política de sus antecesores académicos, los llamados "socialistas de cátedra" (Kathedersozialisten). Por su propia dinámica interna, la teoría crítica se hizo cada vez más compleja, con el efecto involuntario de explicar cada vez mejor la pasividad de las masas y la paradójica estabilidad del capitalismo en medio de las crisis económicas y el ascenso del totalitarismo.

Ya en el exilio, Horkheimer precisó en Teoría tradicional y teoría crítica una de las principales cuestiones que atañen a una crítica inmanente de la sociedad. La teoría tradicional hace como si sus principios fueran tomados de la naturaleza eterna y esencial de las cosas, ignorando metódicamente que la ciencia misma expresa un estado del mundo y está afectada por el desarrollo tecnológico y los intereses económicos. En esta argumentación de Horkheimer se percibe, como estructura básica, la crítica de Hegel al apriorismo kantiano expuesta 
en la Introducción a la Fenomenología del espíritu. El ataque de Horkheimer se dirige contra los positivistas, que eran en ese momento los herederos de la pretensión de objetividad absoluta de la ciencia -el propio Max Weber insistía en un saber sociológico libre de juicios de valor-y hacían depender la solución de los problemas humanos de un supuesto avance irrefrenable de la ciencia, la técnica y la industria guiadas por sus propias leyes.

Los esfuerzos por reanudar las actividades del Instituto en el exilio estadounidense no pudieron evitar una serie de fracturas y transformaciones. La más importante es sin duda el apartamiento de Erich Fromm y la integración de Theodor W. Adorno a la producción filosófica en estrecha colaboración con Horkheimer. La desestructuración económica y organizativa del Instituto, sumada a las angustias, escaseces y nuevos compromisos académicos y editoriales de los miembros contribuyó sin duda a estos cambios. La separación de Fromm, que fue prácticamente un despido, fue precedida por una vehemente carta de Adorno a Horkheimer. Fromm sostenía que la distancia y objetividad que, según Freud, el analista debe mantener ante al sufrimiento del paciente, ocultaba una actitud autoritaria patricéntrica burguesa. La incapacitación del analista para la bondad hacia el paciente era, según Fromm, una ilusión ideológica. Por ello, Fromm llamaba a enmendar las situaciones sociales que causaban el desgarramiento psíquico y a fortalecer en el paciente el deseo de hacer tales cambios, lo que presuponía una actitud solidaria del terapeuta con el paciente así como con todos los afectados por la violencia sistémica. En ello Adorno encontraba el mismo reproche que los intelectuales burgueses hacen a Marx. Adorno denuncia que Fromm opta por una realización sentimental de ideales abstractos en la esfera privada en vez de asumir la gravedad de las contradicciones y madurar en la comprensión de la infelicidad imperante en el mundo real. Este alegato de Adorno anunciaba su ingreso a la gran teoría filosófica en el mismo acto en que causaba la expulsión de Fromm. Durante la década anterior, Adorno se había formado como músico y teórico del arte contemporáneo, había escrito decenas de artículos que condujeron a la construcción de una apología marxista del giro de Arnold Schönberg hacia la dodecafonía. Antes del episodio de las críticas a Fromm, Adorno había completado su libro Teoría de la nueva música, en el que acusaba a Stravinsky de hacer malabares patéticos con los pedazos de la caduca polifonía, lo mismo que hace el dadaísmo con los desechos de la vida moderna destruida. Frente 
a eso, el Pierrot lunaire de Schönberg inicia, según Adorno, el camino de una nueva creatividad de la conciencia irreconciliada que se nutre de la lúcida consideración de la infelicidad del mundo. Horkheimer tenía en sus fondos escépticos y schopenhauerianos motivos bastantes para desconfiar de esta lucidez que no se contenta con nada menos que la transformación universal histórica y desdeña al individuo sufriente. Pero en él prevaleció la perspectiva de Adorno, que auguraba nuevos productos de filosofía social fundamental. Las obras que surgieron de la colaboración Adorno-Horkheimer están caracterizadas por la crítica radical de la moral racional y sus realizaciones públicas y privadas. Según ellos, la crítica no puede partir ya más de ideas realizadas en determinados hechos sociales dados positivamente, como la democracia o la educación moral, menos todavía la revolución, porque estos hechos están contaminados por la misma racionalidad instrumental que ha hecho triunfar al capitalismo. Durante la Postguerra, la generación antitotalitaria en la que se inscriben Hannah Arendt, Karl Popper y Ralf Dahrendorf producía una teoría democrática basada en estudios empíricos de la realidad histórica, social y económica, y por ello enemistada con el ímpetu totalizador del análisis marxista. Mientras tanto, el núcleo duro de la Escuela de Frankfurt, conformado por Horkheimer y Adorno, perpetraba un asalto a la razón completamente intempestivo y quizás por eso mismo pertinente como pensamiento libre en medio de esa época de activismo frenético. El esfuerzo de guerra contra el fascismo, luego la reconstrucción, el espectacular crecimiento económico que le siguió, la formación de las Naciones Unidas y de la Unión Europea, la carrera espacial, la carrera nuclear, el consumismo, el afán de entretenimiento y la sensiblería de un público sediento de novedades y dispuesto a dedicar su forma de vida al éxito y la satisfacción, eran la entrada triunfal de una razón instrumental que ha sobrevivido al hundimiento del totalitarismo y está más allá de la ideología.

En Dialéctica de la llustración, Horkheimer y Adorno penetran con la sospecha de instrumentalización hasta la categoría de sujeto y encuentran que el principio de dominación determina la facultad humana de ser sujeto, es decir, el poder de conocer y valorar objetivamente. La concepción del ser humano como sujeto implica que no hay realidad ni acción que valgan sin la sujeción de estas a los paradigmas del conocimiento y el orden moral, y que por tanto el hombre, para ser tal, tiene que instalarse como un engranaje en 
el mecanismo universal de dominación; según esta concepción, que nuestros autores denuncian, ser dominado y dominar es necesario para poder saber y poder actuar. La crítica afecta entonces a la llustración misma, a la causa común de los filósofos y revolucionarios modernos que llaman a emancipar el saber y la acción de todo autoritarismo y dogmatismo. Ya que tal emancipación se plantea como señorío sobre los propios asuntos, no hace más que internalizar más profundamente la reverencia ante el dominio avasallador; mientras sueñan con librarse de él, se entregan íntimamente a su servicio. A través de la llustración se prolonga lo que ella dice abolir, el imperio del mito. El mito es la disciplina que somete la imaginación y la voluntad a los dictados de la dominación. La halagadora participación imaginaria en las hazañas del héroe enseña a convivir con el miedo transfigurándolo en temor reverente a un modelo de virtud. La Odisea, el mito del regreso de Ulises a su casa, es la escuela del dominio de sí mismo que inspira todas las formas de ascesis y martirio. La llustración, pese a sus juramentos antidogmáticos, no hace más que prolongar esta solemne tradición de autosometimiento, porque entiende la emancipación no como creación de relaciones sociales y personales libres de dominación, sino como señorío sobre los propios asuntos, lo que implica sometimiento estricto a los dictados de la propia conciencia, a las leyes de la naturaleza y del orden social objetivo, incluidas las leyes del mercado, del Estado moderno, de la familia nuclear moderna, etc.

La pasmosa sangre fría de estos análisis, que socavan la moral de la sociedad liberaly agreden incluso su sentido del gusto, no sería posible sin las referencias estéticas de Adorno, en especial su relación con la persona y la obra de Walter Benjamin. Adorno fue el depositario en Estados Unidos de un pequeño cuadro de Paul Klee, el Angelus novus, que Benjamin adquirió con mucho esfuerzo y consideraba su más valiosa posesión ${ }^{6}$. Esta imagen era para Benjamin la suma y cifra de la liberación de la humanidad por el arte. El arte en que Benjamin cree no es el del romanticismo. El arte romántico es una prolongación de la vieja práctica clasicista de glorificar héroes y mártires. El romanticismo desempeñaba la función de legitimación ceremonial en el nuevo elemento de las luchas económicas y políticas por el progreso. Lo hacía mediante personajes que resultaban, pese a las apariencias miserables, rudas, rústicas o exóticas,

${ }_{6}$ Cf. Scholem, Gershom, Walter Benjamin y su ángel, Buenos Aires: FCE, 2003, p. 48. 
profundamente nobles en el sentido moral de la palabra; y con ellos venían sus antagonistas, los malvados patológicos (lo que se dice malvados de novela, de película) que el lector sabe derrotados de antemano. Esa función del arte quedó atrás para los creadores a más tardar con Poe, cuyo sentido para lo infinito dado aquí y ahora como lo extraordinario, fantástico y macabro, lo asombroso sin participación en ninguna trascendencia conocida, ni metafísica ni histórica, pasó a Baudelaire y de este a Proust y a Flaubert. Desde entonces, el arte se centra en la paradoja, contempla la contradicción sin eludir sus efectos devastadores sobre las motivaciones comunes y corrientes, saca de la perplejidad un nuevo tipo de impulso que no fluye reconciliado hacia el consenso público, ese colector de todas las aguas urbanas. En el nuevo arte hay un rescate artístico del valor de la vida individual que prescinde de su inscripción en los libros contables de una razón universal que se realiza mediante la desrealización de las existencias particulares. El recuerdo involuntario, la imagen inconsciente, la situación cotidiana que perece sin reconciliarse con el saber, la ciudad iluminada, el suceso sensacional, el hervidero social de pasiones e ilusiones, la visión infantil o pulsional que reaparece y roba por un momento la atención del adulto son las criaturas efímeras que devora constantemente esa inmensa catástrofe llamada progreso. Redimir a los perdidos es la misión imposible que Benjamin atribuye al Angelus novus representado en el pequeño cuadro de Klee. Un ángel enviado a acompañar el acto de resistencia contra la razón histórica que hay en cada genuina individualidad, uno que volara en dirección contraria al paso del tiempo para presenciar la efímera rebeldía del mortal y apreciar uno por uno a los protagonistas de la vorágine de ínfimo acontecer que llamamos historia, vería detenido su vuelo por el poderoso viento del progreso, no podría más que contemplar admirado la paradoja seductora, como Baudelaire contempla a su musa venal.

Con la influencia de Benjamin, Adorno se dedicó a hacer inventario de la vida dañada, de la deshumanización que penetra hasta los actos reflejos y genera formas de vida llenas de motivaciones ilusas y venales. De esto está hecho el libro más brillante de este período, Minima moralia. Reflexiones desde la vida dañada, donde Adorno hace crítica racional de las formas de vida atrapadas por la razón instrumental, estructuradora del mundo moderno. "La expectativa de posibles ventajas es el enemigo mortal de la formación de relaciones 
humanas dignas"7. Las formas de vida dañadas se reconocen por detalles tan cercanos y cotidianos como que ya no sabemos hacer regalos, que el cumplimiento escrupuloso de las reglas morales de nuestra posición social nos hace indiferentes a los grandes crímenes, que cuando más atareados estamos con el éxito profesional tanto más banales somos, y cuanto más posicionados y posesionados, tanto más obsesivos. Estas pérdidas de dignidad no se echan de menos, pues se las da por resarcidas en el proceso histórico. La reflexión sobre la integridad perdida es un pago que se hace con la propia vida actual para rescatar el tiempo. Rescatar el tiempo, no las almas, de suyo inmortales; el tiempo, no las ideas que, por ser pura identidad, no se adulteran ni corrompen en su esencia; el tiempo y, con él, todo lo que nace para morir, porque lo eterno no precisa redención. En el pensamiento de Adorno, el arte, desde que se separó de toda teología e ideología del progreso, es el elemento del rescate intramundano, que es la única redención posible. La renuncia del arte a su función de pompa y propaganda de valores eternos no ha sido gratuita ni amigable, le ha costado al arte sus repertorios conceptuales con los que simbolizaba y demostraba estar lleno de verdad. Ahora que ha perdido su agraciada posición de intermediario con lo infinito y ya no participa de los fastos de la verdad eterna, ni de la propagación de mensajes edificantes ni sanas doctrinas, ha quedado, como conciencia estética, del lado de la filosofía, esta también despojada de todo contenido fijo, libre de su vieja función de guardiana de los últimos valores eternos, esos que podrían darle todavía a la palabra redención el oscuro atractivo de las cosas santas. Los espectadores se quedan prendidos de las pantallas para no perderse lo sensacional, lo nuevo que ofrece darles a conocer la verdad del laberinto de la urbe, la economía, el erotismo, el poder indescifrable que gravita sobre ellos ${ }^{8}$. Arte y filosofía no hay más en ese mercado de ilusiones, sí en la conciencia crítica que comprende cómo hemos llegado a esto y asiste asombrada al espectáculo que emisores y receptores, productores y consumidores dan juntos.

Si comparamos esta forma microscópica y estética de crítica social con los comienzos de la TCS, la transformación es innegable. Las tareas de la filosofía con que regresaron Horkheimer y Adorno a Alemania y reabrieron el Instituto de

7 Adorno, Theodor, Minima moralia. Reflexionen aus dem beschaedigten Leben, Frankfurt a.M.: Suhrkamp, 200I, aforismo 13: "Schutz, Hilfe und Rat", p. 46.

8 Cf. ibid., aforismo I50: "Extrablatt”, p. 455. 
Investigación Social en 1950 son notoriamente diferentes de las que impulsaron el desarrollo de la TCS en las décadas de 1930 y 1940. No queda rastro de la construcción de un saber empírico sobre la economía, la sociedad, la psique y la cultura mediante métodos como el marxismo y el psicoanálisis. Tampoco sigue en pie el programa de una transformación revolucionaria guiada por un análisis racional de la realidad. Los autores de Dialéctica de la llustración y, de forma algo distinta, Herbert Marcuse, que permaneció en los Estados Unidos, producen una crítica de la cultura con referentes filosóficos e históricos, ya no más investigaciones sociales con pretensiones de objetividad científica y construcción de principios políticos ${ }^{9}$. Pero el cambio más profundo que había acontecido era el referente a la valoración de la modernidad y el programa de la llustración. Las ideas promotoras del mundo moderno dejaron de evolucionar en sus investigaciones hacia formas cada vez más complejas y cristalizaron en aporías y paradojas, formando una continuidad con las alegorías del barroco y la retórica humanística.

En la década de 1960, en medio de un recrudecido debate epistemológico sobre la ciencia social, Jürgen Habermas, asistente de Adorno en el Instituto, se hizo cargo de las cuestiones que la mutación de la TCS arrojaba. Habermas reconstruyó la TCS como teoría del actuar comunicativo y produjo así, según Axel Honneth, "el único nuevo punto de partida que se puede tomar en serio dentro de esta tradición"|0. Habermas trabaja sobre la base de una idea antropológica no marxista, pero tampoco desconectada de los hechos sociales, la idea de la comunicación lingüística. La idea de que el entendimiento mediante el lenguaje constituye las relaciones humanas tiene al mismo tiempo contenido cognitivo, conectado con diversas ciencias, y contenido normativo, con consecuencias prácticas y significado crítico en moral y política. La concepción de los fenómenos sociales que Habermas desarrolló implica un aprovechamiento de la sociología funcionalista de Niklas Luhmann y de la teoría del trabajo alienado de Marx. Frente a la teoría de los sistemas de Luhmann, Habermas sostiene que los individuos aprenden a defender sus actos de comunicación reflexivamente conforme se integran a sistemas sociales complejos que demandan

9 Cf. Honneth, Axel, Crítica del poder. Fases en la reflexión de una teoría crítica de la sociedad, Madrid: Machado, 2009, capítulo I. WBG, 2009, p 17. 
comportamientos estereotipados y regidos por normas abstractas. Frente a la tradición marxista, precisa que la experiencia de la alienación del trabajo desencadena la reflexión sobre las relaciones humanas que se resisten a la cosificación y muestra que dichas experiencias no tienen origen en el trabajo, sino en el libre entendimiento mediante el lenguaje. Habermas escapa de este modo a la estrecha base que Horkheimery Adorno, sus maestros de la Escuela de Frankfurt, compartían aún con Marx, a saber, que la razón humana se configura en la lucha por dominar la naturaleza y satisfacer las necesidades. De la dialéctica de un mundo concebido como puramente material surge la intensa negatividad de la crítica filosófica que percibe los síntomas de la cosificación hasta en los detalles cotidianos y las profundidades del arte. Habermas recibe de esta perspectiva la concepción de la injusticia como patología social y del proceso actual como crisis sistémica en la que la acción se vuelve de nuevo relevante. Pero, a diferencia de sus maestros, sostiene que la comunicación lingüística muestra su contenido normativo al paso que la experiencia humana se enfrenta con los sistemas de condicionamiento de la conducta y dominio técnico de la naturaleza en la producción, esto es, no recibe su sentido de la reflexión sobre el sufrimiento causado por estos procesos, sino al contrario, es una fuente originaria de socialidad presupuesta por ellos.

La estrategia de Habermas es kantiana, reestrena el argumento de que los principios de la razón no se originan en la experiencia, sino que ascienden a la reflexión con ocasión de la experiencia. El contenido normativoy emancipador que hay en la comunicación lingüística se pone en evidencia con ocasión del apogeo de la instrumentalización en la sociedad moderna, a diferencia de la revolución o la creación de formas de vida autónoma, que se entienden como resultados directos de la crisis de la sociedad moderna. La discontinuidad con los propósitos iniciales de la TCS es evidente, pues entonces se trataba de dejar atrás el apriorismo y formular una crítica inmanente a partir del contenido normativo de los mismos hechos sociales. Pese a todas las salvedades que hace Habermas, su concepto de comunicación lingüística, muy cercano al de Karl Otto Apel, no arraiga en los procesos de socialización, sino en una reflexión sobre las funciones del lenguaje que encuentra, entre ellas, la del discurso, que es el hablar libre con pretensiones de validez universal. Habermas admite que el principio de la comunicación, aunque está lejos de ostentar la fuerza motivadora irresistible que Kant atribuye al principio moral, tiene la débil fuerza 
motivadora de las buenas razones. Esta idea cumple la función del principio moral a priori, porque, siendo un hecho antropológico empíricamente investigable, está disponible a la reflexión como instancia autónoma o paradigma frente a la experiencia social. Los límites de su teoría asoman junto a este recurso casi trascendental tomado del pragmatismo. Como filosofía moral y política, incurre, al definir principios, en un cognitivismo casi tan atrevido como el kantiano, y aun más atrevido si se considera que los desarrollos del pragmatismo y de la peripecia epistemológica de Wittgenstein no son precisamente favorables a una objetivación de principios de la comunicación lingüística como la que acontece en la pragmática universal de Habermas. La comunicación cognitivizada por Habermas, que es el corazón de la idea normativa con que critica la sociedad, está más cerca del intento de Gadamer de concebir las ciencias humanas sin las ciencias sociales que de la TCS. De todos modos, los debates que ha sostenido Habermas con prácticamente todas las vertientes filosóficas del siglo $X X$, desde la teoría de la justicia hasta el deconstructivismo y el feminismo, dan prueba de la vitalidad de un pensamiento que ha querido rescatar a la crítica social de las aporías que prácticamente la habían silenciado y habían dejado en su lugar sólo una melancólica crítica radical del mundo moderno.

Los herederos de la TCS han retomado la investigación del rendimiento normativo de las diversas líneas de trabajo de la teoría social. Se impone en los hechos el dictum de Adorno de que no puede haber unanimidad en el método de las ciencias sociales porque la sociedad misma no es unánime. Los estudios de las últimas décadas dan prioridad al estudio de fenómenos negativos, las luchas sociales y las formas de la dominación. Las luchas por el reconocimiento han sido teorizadas por Axel Honneth, las de la paridad participativa, por Nancy Fraser y Seyla Benhabib, y las que se dan en el terreno de los intercambios simbólicos, la distinción y el gusto, por Pierre Bourdieu. Las obras de Michel Foucault surgieron al mismo tiempo que las de Habermas, pero su impacto crítico está en pleno desarrollo a través de su recepción actual. Las teorías de Foucault sobre el poder disciplinario, la normalización y el biopoder revelan en la sociedad moderna un espectro de formas de dominación tan denso y entretejido con las formas de la reflexión que su sentido crítico se expresa en un pensamiento afín al de Adorno en la acritud y melancolía de su ingenio.

Como lo previó Foucault en sus estudios sobre el biopoder, la irrestricta instrumentalización de la vida para el crecimiento económico y el incremento de 
la competitividad se regenera actualmente en múltiples escenarios sociales, que van desde lo local hasta lo global -o, en el análisis de Nancy Fraser, a distinta escala geográfica- después de haber roto su solidaridad keynesiana (de tradición utilitarista) con el Estado nacional. Pero en estos mismos nuevos escenarios se alzan nuevas formas de emancipación, desencadenadas por la globalización misma. La instrumentalización económica y disciplinaria detallada de los móviles privados - que Adorno vio en la vida dañada, Habermas en la colonización del mundo de la vida- ha liberado nuevas fuerzas sociales que, cada vez más conscientes de su poder, se vuelven contra el imperativo de mercantilización y producen nuevas formas de autorrespeto moral, de sentido de la justicia (o mejor dicho, de la injusticia) y de republicanismo. El mismo mercado que disocia a los individuos los ve endurecerse en estrategias para sobrellevar la soledad. En medio de las desinstitucionalizaciones provocadas por un liberalismo económico inescrupuloso, los individuos inventan mezclas chocantes de cooperación y lucha por ventajas competitivas. Se trata del capitalismo de redes", sistemas comerciales basados ampliamente en cooperación gratuita que reducen espectacularmente los costos de transacción. Las formas más agresivas de capitalización se valen de la disposición de las personas a cooperar para obtener nuevos márgenes de ganancia y escapar al estancamiento económico. Luego sucede, como con Wikipedia, que los cooperantes descubren que pueden emanciparse en gran medida de las distorsiones de la cooperación producidas por la apropiación privada del valor del medio de intercambio, y entonces desmercantilizan la cooperación y la institucionalizan, asumiendo crecientes relaciones sociales entre ellos. Esta perspectiva se abre a la investigación crítica de la sociedad en dos direcciones. Primero, en la transformación de las tradiciones de reciprocidad de los países postcoloniales, cuyos pobladores convierten su tenue o nulo disciplinamiento burgués en oportunidad de reinvención de instituciones en el mismo terreno en que prolifera el capitalismo de redes, y después, en la transformación de las tradiciones republicanas de las sociedades burguesas, las que dejan atrás las identidades profesionales, burocráticas y nacionales, así como las virtudes sexistas, y reinventan la solidaridad en diversas escalas.

"Cf. Hartmann, Martin y Axel Honneth, "Paradojas del capitalismo", en: Honneth, Axel, Crítica del agravio moral, Buenos Aires: FCE, 2009, p. 389 ss. 